\title{
Sementes de soja infectadas por Cercospora kikuchii, sob déficit hídrico
}

\section{Soybean seeds infected by Cercospora kikuchii, under water deficit}

\section{Carlos Eduardo PEREIRA'; Marcelo Cláudio PEREIRA²; Joel Guimarães de BRITO JÚNIOR³; José da Cruz MACHADO ${ }^{4}$}

${ }^{1}$ Autor para correspondência; DSc.; Prof. Universidade Federal do Amazonas; Instituto de Educação Agricultura e Ambiente;
Rua 29 de Agosto, 786, Centro, CEP 69800-000, Humaitá, Amazonas, Brasil; e-mail: cepereira.ufam@gmail.com
${ }^{2}$ DSc.; Empresa de Pesquisa Agropecuária de Minas Gerais; e-mail: marcelo.claudio@posgrad.ufla.br
${ }^{3}$ MSc.; Instituto Federal de Minas Gerais; e-mail: joel@cefetbambui.edu.br
${ }^{4}$ PhD.; Universidade Federal de Lavras; e-mail: machado@ufla.br

Recebido em: 08-07-2014; Aceito em: 10-03-2017

\section{Resumo}

O desempenho de sementes de soja e o estabelecimento da cultura em campo podem ser afetados negativamente pela contaminação das sementes por fitopatógenos, principalmente quando as sementes não encontram condições ideais de germinação. Objetivou-se avaliar, neste trabalho, o desempenho de sementes de soja com diferentes níveis de manchamento por Cercospora kikuchii e a eficiência de tratamentos com fungicidas, quando as sementes foram submetidas a déficit hídrico. Sementes foram selecionadas e classificadas quanto à intensidade de manchamento por $C$. kikuchii, em três categorias: sementes sem sintomas ou sem manchas (zero), sementes com 1 a 25\% e com 26 a 50\% da superfície manchada (mancha-púrpura). Em seguida, foram incubadas em meio de restrição hídrica por manitol e submetidas, ou não, a tratamentos com as misturas fungicidas thiabendazole+thiram e carbendazin+thiram. Em laboratório, procedeu-se à análise das sementes por meio dos testes de germinação, frio e de sanidade (Blotter). Ambos os tratamentos fungicidas não erradicaram Cercospora kikuchii quando as sementes se apresentaram com sintomas; entretanto, aumentaram o desempenho fisiológico das mesmas sob estresse hídrico. Em condições de déficit hídrico, durante a germinação, a incidência de manchamento por Cercospora kikuchii, em sementes de soja, aumenta a porcentagem de plântulas anormais infectadas.

Palavras-chave adicionais: Glycine max; mancha-púrpura; tratamento químico.

\begin{abstract}
The soybean seeds performance and the plants establishment in the field may be affected negatively by the contamination of the seeds with phytopatogens, especially under unfavorable conditions for seeds germination. The objective was to evaluate the soybean seeds performance with different stain purple levels and the fungicide treatment efficiency when the seeds are submitted to hydric deficit stress conditions. The seeds were selected and classified by staining intensity in: seeds without stains (zero), 1 to $25 \%$ and 26 to $50 \%$ of the seed surface with purple stain. The seeds were incubated in medium with hydric restriction using mannitol and treated or nottreated with thiabendazol + thiram and carbendazin + thiram fungicides mixtures. In the laboratory the physiologic conditions of the seeds were evaluated by germination, cold and sanity tests. Both chemical treatments did not eradicate the pathogen when the seeds presented high contamination level but they increased physiological performance of the soybean seeds under hydric stress. During germination under water stress conditions, the incidence of Cercospora kikuchii in soybeans increases the abnormal seedlings infected percentage.
\end{abstract}

Additional keywords: chemical treatment; Glycine max; stain purple.

\section{Introdução}

O crestamento foliar de cercospora, disseminado por todas as regiões produtoras de soja (Glycine max (L.) Merril), é uma das doenças que compõem o "complexo de doenças foliares de final de ciclo" (Martins et al., 2004). O agente causal do crestamento foliar é o fungo Cercospora kikuchii, cuja incidência é favorecida por condições quentes e úmidas, desde a floração até a maturidade fisiológica da soja (FAO, 1995).
As perdas causadas por esta doença variam de 15 a 30\% (EMBRAPA, 2000), podendo resultar em até $50 \%$ de perdas resultantes do chochamento das vagens (sem sementes), caso incidência elevada ocorra no estágio de granação (Câmara, 1998). Além disso, a desfolha antecipada, induzida por C. kikuchii, pode reduzir a produção, devido à formação de sementes de menor tamanho (FAO, 1995).

Sementes de soja colonizadas por Cercospora kikuchii podem apresentar redução em sua capacidade de germinação (Pathan et al., 1989), além de originar 
plântulas menos vigorosas e pouco produtivas (Laviolette \& Athow, 1972). Também, Hamawaki et al. (2002) verificaram correlação negativa entre a incidência de C. kikuchii e a germinação e o vigor de sementes de soja. Entretanto, são observados resultados divergentes na literatura, tais como os de Oliveira et al. (1993) e Galli et al. (2005), os quais não verificaram efeito negativo da incidência de $C$. kikuchii na qualidade fisiológica de sementes de soja.

O controle da disseminação e da transmissão de patógenos por sementes pode ser realizado por meio do tratamento com fungicidas (Machado, 2000). Neste sentido, Oliveira et al. (1993) verificaram que o tratamento de sementes de soja com o fungicida thiabendazole é eficiente no controle da cercosporiose. Henning et al. (1991b), trabalhando com o tratamento de sementes de soja com os fungicidas thiabendazole, benomyl e tiofanato metílico, verificaram a eficiência destes benzimidazóis no controle de Cercospora kikuchii, o que foi corroborado por Yuyama \& Henning (1997), para thiabendazole.

Também, o tratamento de sementes de soja com fungicidas confere proteção às sementes quando, logo após a semeadura, o solo possui baixa disponibilidade hídrica, principalmente por períodos prolongados (Pereira et al., 1993). Para que ocorra a germinação das sementes de soja, é necessário que as sementes atinjam cerca de $50 \%$ de teor de água. Neste sentido, em solo com restrições hídricas, quando não se é possível atingir-se o patamar de 50\% de teor de água nas sementes, a germinação é prejudicada, e essas ficam por mais tempo expostas ao ataque de patógenos (Machado et al., 2004).

Em laboratório, a restrição hídrica é realizada colocando-se as sementes em substrato com potencial hídrico ajustado para que a absorção de água pelas sementes atinja níveis em que as fases iniciais da germinação ocorrem, porém não haja emissão da radícula (Heydecker et al., 1975). Esta técnica tem sido utilizada com sucesso na inoculação de fungos em sementes (Costa et al., 2003).

Neste trabalho, objetivou-se avaliar o desempenho de sementes de soja com diferentes níveis de manchamento por Cercospora kikuchii e eficiência do tratamento com os fungicidas thiabendazole + thiram e carbendazin + thiram, quando as sementes são submetidas a déficit hídrico.

\section{Material e métodos}

Foram utilizadas sementes de soja, cultivar Vencedora, selecionadas quanto à intensidade de manchamento por Cercospora kikuchii. As sementes foram coletadas em campo naturalmente atacado. Foram estabelecidas as seguintes classes, por meio do exame visual das sementes: a) sementes sem manchas; b) sementes com 1 a $25 \%$ da superfície com manchas, e c) com 26 a $50 \%$ da superfície das sementes com manchas. Para simulação de condições de déficit hídrico, as sementes foram colocadas em meio de restrição hídrica por manitol, com potencial hídrico ajustado para -1,2 $\mathrm{MPa}$, onde permaneceram por 144 horas, a $25 \stackrel{\circ}{\circ}$ (Machado et al., 2004). Após este período, as sementes foram tratadas com thiabendazole + thiram ou carbendazin + thiram, ambos na dosagem de $200 \mathrm{~mL} / 100 \mathrm{~kg}$ de sementes, e parte das sementes não foi tratada. As avaliações das sementes foram realizadas por meio de:

a) Teor de água das sementes: método da estufa a $105^{\circ} \mathrm{C}$, por $24 \mathrm{~h}$, sendo duas sub-amostras com $40 \mathrm{~g}$ cada por tratamento (Brasil, 2009);

b) Teste de germinação: foram semeadas três repetições de 25 sementes em substrato rolo de papel germitest umedecido, tendo três vezes seu peso, com água (Brasil, 2009). Os rolos foram mantidos em germinador, a $25^{\circ} \mathrm{C}$, por cinco dias, quando foi realizada a avaliação. Os resultados foram expressos em porcentagem de plântulas normais e porcentagem de plântulas anormais infectadas;

c) Teste de frio: a semeadura foi realizada em rolos de papel umedecido, com três vezes seu peso, em água. Foram utilizadas três repetições de 25 sementes por tratamento. Após a semeadura, os rolos foram colocados em câmara fria a $10^{\circ} \mathrm{C}$, por 120 horas, e, posteriormente, transferidos para câmara de germinação, a $25^{\circ} \mathrm{C}$, em regime alternado de luz e escuro (12 horas). Após sete dias nessas condições, foi determi-nada a porcentagem de plântulas normais e de plân-tulas anormais infectadas;

d) Teste de sanidade: as sementes foram incubadas em placas de Petri de $15 \mathrm{~cm}$, com três folhas de papel de filtro umedecido com solução de 2,4 diclorofenoxiacetato de potássio (2,4-D), a $5 \mathrm{ppm}$. Foram utilizadas 25 sementes de cada tratamento por placa, com seis repetições. As placas foram mantidas em sala de incubação, a $20 \stackrel{\circ}{\circ}$, com fotoperíodo de 12 horas, por sete dias, quando foi avaliada a presença de patógenos.

O experimento foi conduzido no delineamento experimental inteiramente casualizado, em esquema fatorial $3 \times 3$, correspondentes a três níveis de manchamento das sementes por $C$. kikuchii e três tratamentos químicos das sementes (sem fungicida, thiabendazole + thiram e carbendazin + thiram). Os dados foram submetidos à análise de variância, e as médias foram comparadas aplicando-se o teste de Tukey a $5 \%$ de probabilidade.

\section{Resultados e discussão}

Pelos resultados do teste de sanidade, observa-se que mesmo as sementes sem sintomas de mancha-púrpura (nível zero) apresentaram contaminação por Cercospora kikuchii, quando não tratadas com fungicidas (Figura 1). Por outro lado, não foram observadas $100 \%$ de incidência de sementes contaminadas, quando todas as sementes apresentavam sintomas de mancha-púrpura (níveis de 1 a $25 \%$ e de 26 a $50 \%)$. 


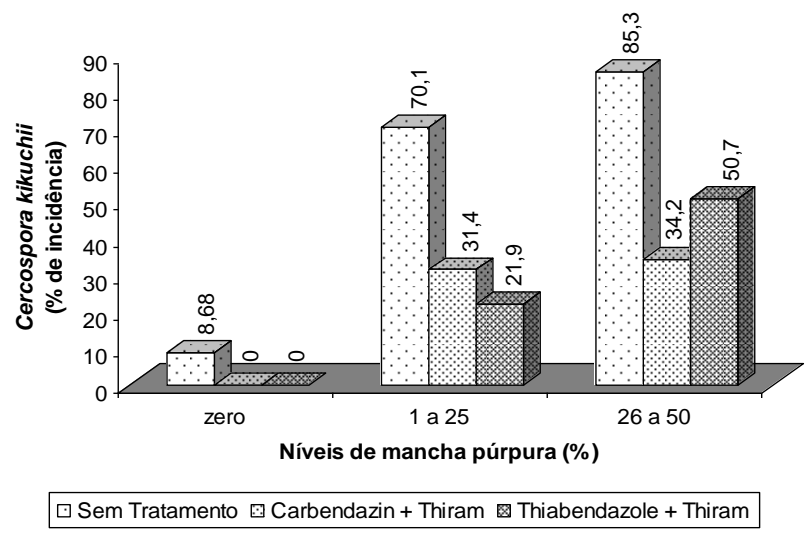

Figura 1 - Porcentagem de sementes de soja contaminadas por Cercospora kikuchii com diferentes níveis de mancha-púrpura (\% da área manchada) e tratadas com fungicidas, após incubação sob estresse hídrico por manitol. Percentage of soybean seeds contaminated by Cercospora kikuchii with different levels of stain purple (\% of stained area) and treated with fungicides after incubation under water stress by mannitol.

Neste contexto, constatou-se que a avaliação visual da presença de mancha-púrpura, como indicativo da infecção por C. kikuchii, não é adequada, pois mesmo em amostras com $100 \%$ de sementes com mancha-púrpura algumas sementes não apresentaram incidência deste patógeno no teste de sanidade.

O tratamento das sementes com os fungicidas carbendazin + thiram ou thiabendazole + thiram erradicou C. kikuchii da amostra de sementes sem mancha-púrpura, ou seja, na amostra de sementes com baixa incidência do fitopatógeno em estudo, os tratamentos fungicidas aplicados foram eficientes, reduzindo a ocorrência de $C$. kikuchii para o nível de $0 \%$. Já para as amostras que apresentavam todas as sementes com mancha-púrpura, independentemente da ocorrência dos níveis 1 a $25 \%$ ou 26 a $50 \%$ da superfície da semente manchada, a incidência deste patógeno foi reduzida quando se realizou o tratamento das sementes com carbendazin + thiram ou thiabendazole + thiram, embora, ainda, fossem observados níveis elevados de infecção (Figura 1).

Neste sentido, constatou-se que, nas semen- tes com sintomas de C. kikuchii, os fungicidas carbendazin + thiram e thiabendazole + thiram reduziram a incidência deste patógeno nas sementes, mas não para o mesmo nível das sementes sem manchapúrpura, mesmo quando não tratadas quimicamente, reafirmando a importância da qualidade inicial das sementes que serão submetidas ao tratamento químico.

Além da ocorrência de C. kikuchii, para sementes sem mancha-púrpura e não tratadas com fungicidas, observou-se contaminação por Phomopsis sojae, Fusarium spp. e Aspergillus spp. (Tabela 1). Quando as sementes foram submetidas ao tratamento com carbendazin + thiram ou thiabendazole + thiram, observou-se, em geral, redução da incidência de Phomopsis sojae, Colletotrichum truncatum, Fusarium sp., Aspergillus spp. e Penicillium spp. Resultados semelhantes foram obtidos por Goulart (2001). Também foi verificado redução da ocorrência de Phomopsis sojae, Fusarium sp. e Aspergillus spp. nas amostras de sementes com mancha-púrpura em relação às sementes que não apresentavam este sintoma.

Tabela 1 - Porcentagem de sementes de soja com diferentes níveis de manchamento por Cercospora kikuchii que apresentaram sinais de Phomopsis sojae (PS), Colletotrichum truncatum (CT), Fusarium sp. (FU), Aspergillus spp. (AS) e Penicillium spp. (PE) após incubação sob restrição hídrica por manitol e tratamento fungicida. Percentage of soybean seeds with different levels of staining by Cercospora kikuchii that showing signs of $\mathrm{P}$. sojae (PS), Colletotrichum truncatum (CT), Fusarium sp. (FU), Aspergillus spp. (AS) and Penicillium spp. (PE) after incubation under water stress by mannitol and treatment with fungicides.

\begin{tabular}{clrrrrr}
\hline \multirow{2}{*}{$\begin{array}{c}\text { Níveis de mancha-púrpura } \\
(\%)\end{array}$} & \multirow{2}{*}{ Tratamento fungicida } & \multicolumn{4}{c}{ Fungos associados às sementes (\%) } \\
\cline { 3 - 6 } & & PS & CT & FU & AS & PE \\
\hline \multirow{2}{*}{ Zero } & Sem tratamento & 28,00 & 0,68 & 36,68 & 23,32 & 0,00 \\
& Carbendazin+Thiram & 0,00 & 0,00 & 7,32 & 18,68 & 0,68 \\
& Thiabendazole+Thiram & 0,00 & 0,00 & 8,68 & 13,32 & 2,68 \\
\hline \multirow{3}{*}{1 a 25} & Sem tratamento & 6,00 & 0,00 & 14,00 & 3,32 & 0,68 \\
& Carbendazin+Thiram & 1,32 & 0,00 & 10,00 & 0,00 & 0,00 \\
& Thiabendazole+Thiram & 0,00 & 0,00 & 6,68 & 0,00 & 0,00 \\
\hline \multirow{2}{*}{26 a 50} & Sem tratamento & 6,00 & 1,32 & 2,00 & 4,00 & 0,00 \\
& Carbendazin+Thiram & 0,00 & 2,68 & 0,00 & 2,00 & 0,00 \\
& Thiabendazole+Thiram & 0,68 & 2,00 & 0,00 & 2,68 & 0,00 \\
\hline
\end{tabular}


Com relação às sementes com mancha-púrpura, para ambos os níveis de manchamento, a redução da ocorrência dos fungos Phomopsis sojae, Fusarium sp. e Aspergillus spp. indica um provável antagonismo por competição entre estes microrganismos e C. kikuchii, o qual, estando em alta incidência nas sementes com mancha-púrpura, acabou suprimindo o crescimento e o desenvolvimento daqueles nas sementes.

Quanto ao potencial fisiológico das sementes, verificou-se efeito significativo dos tratamentos com fungicidas no teste de germinação (plântulas normais e anormais infectadas) e no teste de frio (plântulas normais). O efeito dos níveis de manchamento por Cercospora kikuchii foi significativo apenas para a porcentagem de plântulas anormais infectadas, no teste de germinação. Pelos resultados do teste de germinação, observou-se que, nas sementes tratadas com carbendazin + thiram ou thiabendazole + thiram, a porcentagem de plântulas normais foi significativamente maior em relação às sementes não tratadas
(Tabela 2). Também, verificou-se redução significativa na porcentagem de plântulas anormais infectadas quando as sementes foram tratadas com os mesmos fungicidas.

Por meio do teste de germinação, foi possível constatar, ainda, que as sementes selecionadas para ambos os níveis de mancha-púrpura, de 1 a $25 \%$ ou de 26 a $50 \%$ da superfície da semente manchada, tiveram significativamente maiores porcentagens de plântulas anormais infectadas.

Quanto ao potencial fisiológico das sementes, a maior porcentagem de germinação nos tratamentos que receberam aplicação de carbendazin + thiram e thiabendazole + thiram, provavelmente, seja consequência do controle de $C$. kikuchii e de outros patógenos associados às sementes. Vários trabalhos apontam correlação negativa entre porcentagem de incidência de $C$. kikuchii e a porcentagem de germinação e vigor de sementes de soja (Hamawaki et al., 2002).

Tabela 2 - Porcentagem de plântulas normais (PN) e anormais infectadas (PAI) no teste de germinação e plântulas normais no teste de frio de sementes de soja com diferentes níveis de mancha-púrpura e sementes sem tratamento fungicida, tratadas com carbendazin+thiram ou thiabendazole+thiram, após incubação sob estresse hídrico por manitol. Normal and abnormal seedlings infected in the germination test and normal seedling in cold test of soybean seeds with different levels of stain purple and seeds without fungicide treatment test, treated with carbendazim + thiram or thiabendazole + thiram after incubation under water stress by mannitol.

\begin{tabular}{|c|c|c|c|}
\hline \multirow{2}{*}{ Tratamento fungicida } & \multicolumn{2}{|c|}{ Teste de germinação } & \multirow{2}{*}{$\begin{array}{c}\text { Teste de frio } \\
\text { PN (\%) }\end{array}$} \\
\hline & PN (\%) & PAI (\%) & \\
\hline Sem tratamento & $54 \mathrm{~b}$ & $28 \mathrm{a}$ & $63 \mathrm{~b}$ \\
\hline Carbendazin+Thiram & $72 \mathrm{a}$ & $9 \mathrm{~b}$ & $71 \mathrm{a}$ \\
\hline Thiabendazole+Thiram & $78 \mathrm{a}$ & $10 \mathrm{~b}$ & $72 \mathrm{a}$ \\
\hline \multicolumn{4}{|c|}{ Níveis de mancha-purpura } \\
\hline Sem manchas & $70 \mathrm{a}$ & $7 a$ & $70 \mathrm{a}$ \\
\hline 1 a $25 \%$ & $69 \mathrm{a}$ & $22 \mathrm{~b}$ & $71 \mathrm{a}$ \\
\hline 26 a $50 \%$ & $65 a$ & $19 b$ & $65 a$ \\
\hline
\end{tabular}

Médias seguidas pela mesma letra, para o fator tratamento químico e níveis de mancha-púrpura isoladamente, não diferem estatisticamente entre si, pelo teste de Tukey, a 5\% de probabilidade.

A infecção das sementes de soja por fungos fitopatogênicos, como Cercospora kikuchii, pode reduzir o potencial de germinação, seja por morte das sementes, seja por formação de plântulas anormais (Machado, 2000). Neste sentido, observou-se que a redução da incidência do fungo $C$. kikuchii nas sementes pelos fungicidas carbendazin + thiram e thiabendazole + thiram refletiu também na redução da porcentagem de plântulas anormais infectadas observadas no teste de germinação, e, consequentemente, as sementes submetidas ao tratamento com fungicida apresentaram maior porcentagem de germinação. Assim, verifica-se que as sementes de soja com manchamento por C. kikuchii, submetidas a condições de déficit hídrico logo após a semeadura, poderão ter elevada porcentagem de plântulas anormais infectadas, mesmo que após cinco dias de restrição hídrica ocorram condições ideais de germinação.

Segundo Henning et al. (1991a), pode-se recomendar 0 tratamento de sementes de soja, quando há possibilidade de ocorrência, durante a semeadura, de condições edafoclimáticas adversas que impedem a rápida germinação de sementes de soja. Acredita-se, portanto, que o tratamento das sementes de soja com os fungicidas carbendazin + thiram ou thiabendazole + thiram, visando à proteção das sementes em condições de déficit hídrico logo após a semeadura, pode contribuir para a formação de um estande adequado.

No teste de frio, foram observados resultados semelhantes ao do teste de germinação, sendo que as sementes tratadas com carbendazin + thiram e thiabendazole + thiram tiveram significativamente maior porcentagem de plântulas normais em relação às sementes não tratadas (Tabela 2).

Após o período de incubação das sementes de soja sob estresse hídrico por manitol, a utilização de baixas temperaturas, associada ao substrato umedecido no teste de frio, ampliou o período de estresse das sementes, tornando-as mais suscetíveis a danos causados por patógenos e, nestas condições, verificou-se a proteção das sementes 
pelo tratamento de fungicida com carbendazin + thiram e thiabendazole + thiram, promovendo aumento significativo da porcentagem de plântulas normais.

\section{Conclusões}

Carbendazin + thiram e thiabendazole + thiram não erradicam Cercospora kikuchii quando as sementes apresentam sintomas; entretanto, aumentam o desempenho fisiológico das sementes de soja.

Em condições de déficit hídrico durante a germinação, a incidência de manchamento por Cercospora kikuchii em sementes de soja aumenta a porcentagem de plântulas anormais infectadas.

\section{Referências}

Brasil (2009) - Ministério da Agricultura, Pecuária e Abastecimento. Regras para análise de sementes. Brasília. 399p.

Câmara GMS (1998) Desempenho produtivo dos cultivares de soja IAC-17, IAC-12 e IAC-19, semeados em três épocas de semeadura e em cinco densidades de plantas. ESALQ (Tese Livre Docência).

Costa MLN, Machado JC, Guimarães RM, Pozza EA, Oride, D (2003) Inoculação de Fusarium oxysporum f. sp. phaseoli em sementes de feijoeiro através de restrição hídrica. Ciência e Agrotecnologia 27(5):10231030.

EMBRAPA (2000) - Empresa Brasileira de Pesquisa Agropecuária - Centro Nacional de Pesquisa de Soja. Recomendações técnicas para a cultura da soja na Região Central do Brasil 2000/01. Londrina. EmbrapaCNPSo. (Documentos, 146).

FAO (1995) - Food and Agriculture Organization. El cultivo de la soja en los trópicos: Mejoramiento y producion. Roma. 254p.

Galli JA, Panizzi RC, Fessel AS, Simoni F, Ito MF (2005) Efeito de Colletotrichum dematium var. truncata e Cercospora kikuchii na germinação de sementes de soja. Revista Brasileira de Sementes 27(1):182-187.

Goulart ACP (2001) Incidência e controle químico de fungos em sementes de soja em alguns municípios de Mato Grosso do Sul. Ciência e Agrotecnologia 25(6):1457-1466.

Hamawaki OT, Juliatti FC, Gomes GM, Rodrigues FA, Santos VLM (2002) Avaliação da qualidade fisiológica e sanitária de sementes de genótipos de soja do ciclo precoce/médio em Uberlândia, Minas Gerais. Fitopatologia Brasileira, Brasília 27(2):201-205.
Henning AA, Krzyzanowski FC, França Neto JB (1991a) Eficácia do tratamento de sementes de soja com fungicidas no controle dos principais fungos fitopatogênicos transmitidos pela semente. Informativo ABRATES 1(4):98.

Henning AA, Krzyzanowski FC, França Neto JB, Yorinori JT (1991b) Tratamento de sementes de soja com fungicidas. Embrapa-CNPSo, 4p. (Comunicado Técnico, 49).

Heydecker W, Higgins J, Turner YJ (1975) Invigoration of seeds? Seed Science and Technology 3(3/4):881888 .

Laviolette FA, Athow KL (1972) Cercospora kikuchii infection of soybean as affected by stage of plant development. Phytopathology 62:771.

Machado JC, Oliveira JA, Vieira MGGC, Alves MC (2004) Uso da restrição hídrica na inoculação de fungos em sementes de algodoeiro (Gossypium hirsutum L.). Revista Brasileira de Sementes 26(1):6267.

Machado JC (2000) Patologia de sementes: significado e atribuições. In: Carvalho NM, Nakagawa J. Sementes: ciência, tecnologia e produção. $4^{\circ} \mathrm{ed}$. FUNEP. p. 522-588.

Martins MC, Guerzoni RA, Câmara GMS, Mattiazzi P, Lourenço AS, Amorim L (2004) Escala diagramática para a quantificação do complexo de doenças foliares de final de ciclo em soja. Fitopatologia Brasileira 29(2):179-184.

Oliveira JA, Machado JC, Vieira MGGC, Brandão Junior DS (1993) Transmissibilidade e danos causados por Cercospora kikuchii em sementes de soja. Revista Brasileira de Sementes 15(1):97-100.

Pathan MA, Sinclair JB, Mcclary RD (1989) Effects of Cercospora kikuchii on soybean seed germination and quality. Plant Disease 73(9):720-723.

Pereira LAG, Costa NP, Almeida AMR, França Neto JB, Gilioli JL, Henning AA (1993) Tratamento de sementes de soja com fungicida e/ou antibiótico, sob condições de semeadura em solo com baixa disponibilidade hídrica. Revista Brasileira de Sementes 15(2):241-246.

Yuyama MM, Henning AA (1997) Avaliação de thiabendazole e thiram no controle dos principais fitopatógenos em sementes de soja. Revista Brasileira de Sementes 19(2):266-269. 